\title{
The Impact of Management Accounting on the Improve- ment of Human Resources Management. An Italian Case Study in the IT Sector
}

\author{
Aprile Roberto \\ Department of Management, University of Bologna, Bologna, Italy
}

\section{Email address:}

roberto.aprile4@unibo.it (R. Aprile)

To cite this article:

Aprile Roberto. The Impact of Management Accounting on the Improvement of Human Resources Management. An Italian Case Study in the IT Sector. Journal of Human Resource Management. Special Issue: Challenges and Opportunities in the Performance Measurement and Control Systems of Human Resources Management for the Services Industry. Vol. 3, No. 2-1, 2015, pp. 33-38.

doi: 10.11648/j.jhrm.s.2015030201.15

\begin{abstract}
Since economy is facing a new era, slightly and increasingly shifting form the industrial period to the service one, also the scientific world is changing to face the new information and managerial requirements. Human resources (HR) and intangible factors represent ones of the most important factors, but it is quite difficult to evaluate if the company is employing them in the best way to guarantee the company to generate value in the short, but also in the middle and long terms. It traditional industrial companies are more focused on the measurable productivity and effectiveness of the work of the HR, traditional tools and framework could face some difficulties in the application in this changed context. This paper after summarizing the recent traditional theoretical frameworks, their evolution and the connected changes in the management accounting and management control systems, analyzes a case study of a successful Italian Small and Middle Entity (SME) operating in the Information Technology sector (IT) recently introducing formal instruments for helping the company in guaranteeing both short term economic results and long term performance and innovation by the means of effective and useful R\&D investments. The paper finds that even 'old traditional tools' of management accounting and managerial accounting can be extremely useful, if adapted, to optimize and rationalize the use of human resources. They can in fact provide useful information for the distribution of the working load, for the process analysis and to define the productivity of the worked hour. Management accounting can supply information useful to address the activity of the Sales area, helping it in its pricing activity, but also in identifying which human resources are underemployed and, as a consequence, available for working in new tasks. It also supplies some useful insights to better manage and quantify resources and costs connected to $R \& D$ projects.
\end{abstract}

Keywords: Management Accounting, Human Resources, Optimize Workload

\section{Introduction}

"Commentaries on major economic cycles in human civilization have identified three ages of economic evolution: the agrarian age, the industrial age, and the information age (e.g. [1], [2]). [...]. The ages partially overlap and therefore cannot be exactly positioned on a tie scale. Differences also exist between different countries' paces of development. [...] we presently find ourselves in a transitional stage between the industrial and the information age. This I reflected in the way in which our thinking about management and accounting is changing" [3: 112].

This period is characterized by an increasing relevance of the service sector that requires a different approach compared with the industrial one. As a consequence also accounting and control are slightly modifying and are trying to find their right equilibrium between the demands for flexibility and control, and in some ways between the short period and the middle and long one. The accounting information and control systems in contemporary organizations must be able to support this dual role. All these changes "have initially also been perceived as signals of the immediate obsolescence of the old rules of the 'organization game'. However, their effects on traditional accounting and control systems in organizations remain to be explored" [3: 113-114]. 
The thrust of this paper is to analyze the impacts that an updated management accounting system, and specific tools can give to firms in terms of information and in order to detect specific organizational needs with reference to the human resources management.

To achieve this purpose, after examining the main theoretical frameworks, the paper will focus on a specific case study analyzing a company developing software for customers which produce industrial machineries (Business to business activity).

The results could be helpful in terms of connections between management accounting and organizations, and in order to supply companies with tools able to generate useful information for the management of the different areas (in particular CEO, Marketing, Production, CFO, R\&D, HR, Project Managers).

Nowadays many service companies are facing the problem of transforming not well defined inputs in not well defined outputs, and this is changing the traditional way of controlling, typical of the industrial era. Firms operating in the so called 'new economy' and in particular in the service sector, are "knowledge-intensive and their employees are knowledge workers such as technicians who monitor computer-controlled machines instead of machine operators [4], [5], [6]. The new organization gives its knowledge workers discretion over their own actions, instead of demanding obedience to external norms [7]" [3: 116]. The same authors specify that "the new organization, because of its needed flexibility has less well-defined tasks than the traditional organization because tasks may be non-routine, ambiguous, and complex [8], [9]. As a result, employees must have greater abilities to work and think independently. [...]. Perfect control in this type of organization is not to achieve a predetermined plan, but to realize its potential" [3: 117].

We can also find the same results in Andon et al [10] in which the authors analyze the case of a call center and find that old traditional control measures are not functional to guarantee the success of the company.

In other words, the traditional approach of "thermostat" suggested by Anthony [11: 8] is shifting to a knowledge control and the resources adopted to achieve the purposes of the entity (in particular time and money).

However, this contribution doesn't intend to define a new framework, but only to adopt and adapt traditional management accounting tools (and Italian literature has a great tradition of this issue: D'Ippolito, Paganelli, Coda, Sòstero, just to recall some main contributions [35], [36], [37], [38]).

Since the traditional management accounting techniques and control are still pervasive, many aspects of such approaches are still easy to be found also in the service sector and in the new economy. This is possible since traditional organizational roles for accounting can be useful and applicable also nowadays.

Andon et al analyze case study addressing a call center firm that operates in the service sectors. The authors analyze the case of a call center and specify that "managing time, and managing the ways in which the call girls used their time, became the key to control in this organization" [10: 140].

The paper is structured in 5 paragraphs. Paragraph 2 contains the background analysis and the literature review; par. 3 exposes the methodology and par. 4 analyzes the case study. This paragraph is divided in three parts: the description of the company (4.1), the analysis of its information needs and of the useful management accounting tools (4.2), and the findings of the case study (4.3). Paragraph 5 contains the conclusions of the paper.

\section{Background Analysis and Literature Review}

There are different streams of research converging on this issue, some from the traditional management accounting and management control background, others from the Strategic human resource management (among the other Fombrun et al., Beer et al., Kamoche) [12], [13], [14], others from the resource based view (Penrose, Rumelt, Wernerfelt, Grant, Barney, Amit and Schoemaker) [15], [16], [17], [18], [19], [20], and all have the purpose to maximize the profitability of the companies.

Traditional management control frameworks find their origin within the so called 'industrial era' and are mainly based on the contributions of Ouchi [21], Merchant [22], [23] and Simons [24], [25] and nowadays there is a great effort to try to contextualize these conceptual frameworks at the operational level, in the 'new economy'. The traditional studies are more focused on efficiency and effectiveness and are in some ways involving a short time dimension and a top-down approach. Recent developments are shifting the approach to the value creation ability (see also the Integrated Reporting Framework), [26], on the importance of knowledge, resources and competencies (Kamoche) [27].

Some theoretical underpinning of the management control system theories are rooted in contingency (Chapman, Chenhall) [28], [29] and agency theories (Baiman) [30], empathizing a static, cross-sectional view of the organizations suggested by Davila [31]. As pointed out by the same author "Existing research taking an organizational view of management control systems (MCS) focuses mostly on the population of medium and large firms where formal systems have long been established and play a major role in structuring the organization and implementation strategy [32], [33]" [31: 223]. He also adds that "this transition point, when companies move from an informal management approach to the need for formal management tools, is most visible in the population of small growing firms. Growing companies are faced quickly with the tensions associated with informal processes and the challenge of successfully mastering the transition into formal control systems" [31: 224).

The need of concrete application of the theory also emerges in the contribution of Andon et al. [10], in particular 
with reference to the new economy characterized by a strong relevance of the service sector.

\section{Methodology}

The increasing need of a concrete application of the different theoretical frameworks and management tools suggest to adopt a case study approach [34], for this research as already done by Andon et al. up mentioned.

The case study analyzes a successful SME operating in Italy in the software industry. The choice of the case study is based on the following aspects. The company represents a growing firm passing by a system of informal control to more structured forms of formal control. The referred is a company characterized by the so called 'handcrafted industry' that represents a typical approach of many Italian firms. Such companies achieve success all over the world, also in sectors where other big International competitors are working, but differentiating themselves for the level of customization and innovation that in many cases is difficult to fulfilled by larger companies.

Knowledge and high level of labor force, in addition to the wide vision of the CEO (the founder) are a key success factor. There is also the need to satisfy client's current requirements, but also to innovate and to be able to offer new solutions and new products useful for customers. Therefore there is a high amount of investments in R\&D. Human resources represents one of the main costs of the company.

All these aspects suggest to choose the analyzed company as a case study.

The case study is based on interviews to the founder of the company (Ceo), its $\mathrm{Cfo}$, its sales manager, its operation manager, and on the analysis of the data emerging from the ERP software and from the financial statements.

\section{The Case Study}

\subsection{The company}

The case study analyzes a small and middle entity (SME) operating in Italy in the software industry. The owner of the company is the founder with the passion for innovation and for creating something specific and useful that other companies are not able to do. The firm develops software (in some cases with the addition of the hardware or other complementary elements), for industries operating in the production of machinery or plants addressed to different sectors. Such products are exported all over the World from the clients of 'our' firm and this situation sometimes requires that the technicians of the software company should go abroad for the installation or for other aspects that are necessary. Since there is a strong relationship with the clients in many cases it can be transformed in a sort of informal partnership. The purpose of the company is in fact to establish long term relationships with its own clients.

Since the company works with different technologies and for different sectors, there is a pool of programmers that are working directly for specific commissions, but also for implementing new technologies or specific software that client are not requiring yet, but that can become part of the future business. Such activities are considered as Research and Development. There are not specific programmers working only for the R\&D area, since everyone is also working for the customers' commissions.

Each programmer should indicate in an integrated data base, the hours dedicated to each commission or to R\&D.

Programmers are directed by a manager that is also strictly involved with the problem solving connected to the specific needs of the customers.

\subsection{Discussion}

Basing on the documents analyzed and on the interviews, it emerges that most of the working time of many programmers is devoted to R\&D activities. In some cases some projects are requiring more time than expected (compared with the planned time of activities) with a negative impact on the company's results, in terms of increase of costs and of time production. All information emerging from the current reports are expressed both in terms of hours and of total costs.

The labor cost, and in particular the cost of programmers represents a relevant part of the costs of the firm. It is a fixed cost and only for specific tasks the company outsources some activities. In other cases the firm gives application to joint research projects with the university.

The more relevant necessities emerging from the interviews, with reference to the human resource management, are the following ones:

a) to calculate the cost of the worked hour to attribute to the client and to the R\&D projects;

b) to optimize productivity of the programmers;

c) to help the plan of the workload and give information to the sales manager about which programmers have more available time to dedicate to the clients.

The current cost per hour filled in the database for the quantitative determinations is calculated dividing the total annual cost of each programmer, by the number of worked hours. Multiplying this result for the hours dedicated to each project, the company could determine the cost attributable to each project. At the end of the year (and obviously during the year), the company can determine the total amount of resources used for $\mathrm{R} \& \mathrm{D}$ projects.

As Collins [39] points out, "resources must be evaluated against the competition since only a competitively unique and superior competence can be a source of economic value" [27: 214-215]. This aspect finds a concrete application in the firm since some programmers, with specific competencies were hired and are still working there just to allow to offer a service to well identify clients, even if these clients are not occupying all their working time.

This is one of the aspects that suggests to differentiate the cost of the worked hour depending on the different object of the analysis. In fact, such cost could assume different meanings and values. It could be calculated basing on the 
theoretical worked hours, or on the effective worked hours, or on the 'productive hours' or even on the 'saleable' hours. Each kind of value could be useful to give a reply to different information needs.

The first two categories are usually adopted in the industrial sector since its workers generally use their time for well-defined and specific tasks. On the contrary, the last two categories of values (that are usually less common within the companies), are very important in the service sector in which the working time of employees is not always dedicated to 'productive activities' and the time necessary to achieve an object is really flexible and difficult to be identified. Self-assessment is, as a consequence, really important both in terms of budgeting the time necessary to accomplish each commission, and for the analysis of the results obtained.

Meantime it is necessary that a supervisor could have an 'order of magnitude' of the time required and of the resourced to be used. To achieve this purpose it is necessary that the work could be planned identifying specific steps and that for each step the expected time of accomplishment should be quantified in advance.

This is very useful in particular for middle and long term commissions, whereas for the short ones it could be enough to quantify the total amount of expected time.

This aspect allows to achieve meantime different purposes. On one side, it could be useful to know in advance the expected 'free time' that the programmers could dedicate to R\&D (now the company has to wait till the end period to calculate how long programmers have been involved in R\&D activities, with the connected economic quantification of their cost). Nowadays R\&D represents a sort of differential value calculated as the difference between workable hours and the hours used for specific commissions. It is in fact quite obvious that the employees would not fill the database underlying 'unproductive time', but they will probably fill it adopting the 'escape option' represented by R\&D. On the other side, this information could help the selling process, since the salespersons, knowing in advance the free time of the programmer could address the sales in terms of timing and in terms of kind of service that could be useful to fill the working time of each employee. By this way all the organization of the company can take advantage since it help avoiding that some programmers could be too much busy and other should have too much spare time that for sure do not help productivity (Parkinson's law).

In other words, the company could know in advance and better the expected workload of each programmer and use better its eventual spare time.

Another aspect that is generally not considered within the database is that even if programmers are paid for 8 hours per day, they probably face not productive moments considering the time to switch on and to switch off the computer, the time for the coffee break or other personal needs. It is easy that there is an average of about more than half an hour per day of unproductive time.

As a consequence, to define the annual time that should be subtracted by the productive hours it is necessary to define the average number of days worked each year. It consists, in an Italian company of about 210 days (each year there are 52 Sundays, 52 Saturdays, about 30 days of holidays, 11 Festivities, 7 days off sick, some days of paid furlough). In this case we can see that the average number of hours worked is not an useful tool to determine the cost of the hour for giving an estimate to customers, since it underestimates the real cost for the entity.

The second profile regards the timesheets filled by programmers: since it is obvious that they would consider as productive each moment of their day, all the 8 daily worked hours will be attributed to a project. Which kind of project? If they are working for a specific commission the result is that they would be better controlled since there is a comparison with the expected worked hours and in many cases there will also be a double-check from the client.

On the contrary, $R \& D$ projects allow more freedom to programmers since it is quite impossible to judge the quality of the work. This is strictly related to the fact that such projects represents pioneering works difficult to be compared with any specific standard.

In other words R\&D projects could represent a sort of 'cop out' for programmers to justify eventually unproductive time.

Another aspect to be considered is that the work of the programmers is strictly connected with the project sold by the company. In other words, if the company sells many projects (and connected working hours), programmers will be most involved in 'saleable hours' than in R\&D research. This means that if the number of hour sold was restrained, the number of hours devoted to R\&D would automatically increase, even if there is any specific reasons.

After this control approach based on the time measure, we can focus on the economic quantification of previous aspects.

One interesting information for the company is represented by the cost of the 'productive hour'. This can be determined dividing the total cost of the programmers for the theoretical hours that they can really work. The denominator should be cleaned of the 'not working time', such as the one specified before, but also by the time used for training and other aspects.

This calculation is useful to quantify the cost to be attributed to commissions and to $\mathrm{R} \& \mathrm{D}$, if multiplied for the effective worked hours (cleaned of the eventual spare time).

If on the contrary a programmer is not really busy for all the time, but its work is necessary to accomplish specific tasks and work for specific customers, it could be useful to calculate a specific configuration of cost. Its cost per hour should be calculated dividing its total cost by the number of hours that the programmer is effectively working for the commissions. Otherwise the cost on which basing the offer to the client would be not sufficient to cover the whole cost of the employee (or at least it should be a well-aware choice of the management to practice a price that is already known that is able to cover or not the cost of the human resources).

Following the previous ways of reasoning, in the analyzed 
case study it emerges that in this case of organization and company, it is better to quantify the specific cost for each programmer avoiding to base on average costs of the working group that could not be useful for understanding the way in which each resource is giving its contribution to the short and long term performance of the company (each programmer, in fact has specific competencies and works on specific tasks).

\subsection{Findings}

Combining financial data, accounting, management accounting and management control systems in a consistent way it emerges the possibility to achieve useful information that can help the company in managing management human resources, allowing to realize better economic performance in terms of costs and revenues (whose determination is strictly connected with the correct quantification of the costs incurred by the company).

The process generally requires two steps. The first is a forward looking quantification of the time necessary to accomplish different tasks, even if they are related to specific commissions or to more wide R\&D projects. By this way, comparing the expected time with the effective final used time, there is the possibility to adopt a sort of 'thermostat' as Antony suggested.

This means that also traditional management accounting tools can be used for the companies of the 'new economy'.

The way of using the information is anyway less rigid since it can be considered as just an alarm bell for the programmer each self and for the supervisor that can help with his experience in managing better the task or managing the emerged problems (which can be eventually be transformed in more revenues if the customer would be considered responsible of such problems as in the case of changes in its requirements and so on).

Self-assessment and top-down assessment could represent a good combination for the service sector in which there is the necessity of stimulating the autonomy of human resources, but meantime to allow the managers to control in advance the direction of the company and the expected results.

Planning the human resources usage can allow also to the sales manager to plan the orientation of the sells with the purpose to 'exploit' in the best way all the resources held by the company.

So doing also R\&D would become more aware and be planned in advance rather than be done in the 'spare time' or the programmers.

Also in this cases traditional tools of management accounting could be still useful nowadays if adapted to current needs. The cost per hour could be in fact calculated basing on different denominators, each one with a specific meaning useful to adopt different choices.

In all these aspects the use of ERP systems helps, or in some cases could become necessary, to accomplish these objectives.

\section{Conclusions}

In the 'new economy era' characterized by the increasing importance of the service sector, the traditional application of the traditional frameworks and tools of management accounting and control could be useless or even dangerous if not adopted and adapted in the light of the different information needs.

Since human resources represents one of the main key success features and one of the most relevant cost of the entity, this paper is focused on the analysis of this specific issue.

Basing on the case study of a company working in the IT sector (a SME), the paper analyzes how to monitor the use of the time of programmers, considering that they represent one of the main resources of the company (RBV approach).

The paper finds that even 'old traditional tools' of management accounting and managerial accounting can be extremely useful, if adapted, to optimize and rationalize the use of human resources. They can in fact provide useful information for the distribution of the working load, for the process analysis and to define the productivity of the worked hour.

Management accounting can supply information useful to address the activity of the Sales area, helping it in its pricing activity, but also in identifying which human resources are underemployed and, as a consequence, available for working in new tasks.

It also supplies some useful insights to better manage and quantify resources and costs connected to $R \& D$ projects.

\section{Acknowledgments}

I would thank the Company for participating to this case study and in particular its Founder and Ceo, its Cfo, its Sales manager, and its Operation Manager.

I would also thank the Reviewers for all suggestions that helped me in improving the paper.

\section{References}

[1] Hope J. and Hope T., Competing in the Third Wave. The Ten Key Management Issues of the Information Age (Boston, MA: Harvard Business School Press), 1997.

[2] Toffler A., Powershift: Knowledge, Wealth, and Violence at the Edge of the 21 st Century, New York, Bantam Books, 1990.

[3] Hartmann F. and Vaassen E., The Changing role of Management Accounting and Control Systems. Accounting for Knowledge Across Control Domains, in "Management Accounting in the Digital Economy", Edited by Bhimani A., Oxford University Press, 2008.

[4] Drucker P.F., 'The Coming of the New Organization' Harvard Business Review (January-February), 1993, pp. 45-53.

[5] Nonaka I. and Takeuchi H., The Knowledge-Creation Company. How Japanese Companies Create the Dynamic of Innovation (New York: Oxford University Press), 1995. 
38 Aprile Roberto: The Impact of Management Accounting on the Improvement of Human Resources Management. An Italian Case Study in the IT Sector

[6] Quinn J.B., Intelligent Enterprise: A Knowledge and Service Based Paradigm for Industry, New York: The Free Press, 1992.

[7] Clegg S.R., Modern Organizations - Organizations Studies in the Postmodern World, London: Sage Publications, 1990.

[8] Peters T.J., Thriving on Chaos, New York, New York, Knopf, 1987.

[9] Volberda H.W., 'Toward the Flexible Form: How to Remain Vital in Hypercompetitive Environments', Organization Science, 7/4,1996, pp. 359-74.

[10] Andon P, Baxter J. and Chua W.F., 'Management Accounting Inscriptions and the Post-Industrial Experience of Organizational Control', in "Management Accounting in the Digital Economy”, Edited by Bhimani A., Oxford University Press, 2008.

[11] Anthony R.N., Planning and Control Systems. A Framework for Analysis, Boston: Harvard Graduate School of Business, 1981.

[12] Fombrun C., Tichy N.M. and Devanna M.A (Eds), Strategic Human Resource Management, New York, Wiley, 1984.

[13] Beer M., Spector B., Lawrence P., Millis D.Q. and Walton R.E., Managing Human Assets, New York, Free Press, 1984.

[14] Kamoche K., Toward a model of HRM in Africa, in Shaw, J.B., Kirkbride, P.S., Rowland, K.M. and Ferris, G.R. (Eds), Research in Personnel and Human Resource Management. Greenwich, Con.: JAI Press, 1993, pp. 259-278

[15] Penrose E.T., The Theory of the Growth of the Firm, Oxford, Blackwell, 1959.

[16] Rumelt R.P., Towards a theory of the firm, in Lamb, R.B. (Ed.), Competitive Strategic Management, Englewood Cliffs, New Jork, Prentice-Hall, 1984, pp. 556-570

[17] Wernerfelt B. (1984), A resource-based view of the firm, in Strategic Management Journal, 5, 171-180.

[18] Grant R.M., The resource-based theory of competitive advantage: implications for strategy formulation, California Management Review, 33, (3), 1991, pp. 114-135.

[19] Barnay J.B., Firm resources and sustained competitive advantage, in Journal of Management, 17, 1991, pp. 99-120.

[20] Amit R. and Schoemaker P.J.H., Strategic assets and organizational rent, in Strategic Management Journal, 14, 1993, pp. $33-46$.

[21] Ouchi W.G., A Conceptual Framework for the Design of Organizational Control Mechanism, Management Science (September), 1979, pp. 833-848.

[22] Merchant K.A., The Control Function of Management, Sloan Management Review, Summer, 1982, pp. 43-55.
[23] Merchant K.A., Modern Management Control Systems, Upper Saddle River, Prentice Hall, 1998.

[24] Simons R., Levers of Control. How Managers Use Innovative Control systems to Drive Strategic Renewal, Boston, Harvard Business School Press, 1995.

[25] Simons R., Performance Measurement and Control Systems for Implementing Strategy, Upper Saddle River, Prentice Hall, 2000.

[26] IIRC, The International $<$ IR $>$ Framework, 2013

[27] Kamoche K., Strategic Human Resource Management within a Resource-Capability view of the Firm, in Journal of Management Studies, 33 (2), 1996, pp. 213-233.

[28] Chapman C., Reflections on a contingent view of accounting, in Accounting, Organizations and society, 22, 1997, pp. 189-205.

[29] Chenal R.H., Management control systems design within its organizational context: Findings from contingency-based research and directors for the future, in Accounting, Organizations and Society, 28, 2003, pp. 127-168.

[30] Baiman S., Agency research in management accounting: a survey, in Journal of Accounting Literature (Spring), 1982, pp. 154-213.

[31] Davila T., An exploratory study on emergence of management control systems: formalizing human resources in small growing firms, in Accounting Organizations and Society, 30, 2005, pp. 223-248

[32] Langfield-Smith K. (1997), Management control systems and strategy: A critical review, in Accounting, Organizations and society, 22, 207-232.

[33] Luft J. and Shields M.D., Mapping management accounting: Graphics and guidelines for theory-consistent empirical research, in Accounting, Organizations and Society, 28, 2003, pp. $2 / 3$

[34] Yin R.K., Case Study Research. Design and Methods. Third Ed. Sage Publications, 2003.

[35] D'Ippolito T., La contabilità analitica d'esercizio svolta secondo il tipo combinato preventivo standard e consuntivo, Palermo, 1961

[36] Paganelli O., La contabilità analitica d'esercizio. Seconda Edizione, Pàtron Editore, Bologna, 1973.

[37] Coda V. (1968), I costi di produzione, Giuffrè, Milano.

[38] Sòstero U. (1991), Analisi dei costi: le logiche di attribuzione, Cedam, Padova.

[39] Collins D.J., A resource-based analysis of global competition: a case of the bearings industry, in Strategic Management Journal, 12, 1991, 48-68. 